\title{
Mesenchymal Stem Cell Injection Achieves Closure of Chronic Wound in Canine Patient: A Case Report
}

\author{
Amanda Baracho Trindade Hill* and Jonathan Edwin Baracho Trindade Hill \\ CellTech-stem cell technologies, Brazil
}

*Corresponding author: Amanda Baracho Trindade Hill, CellTech-stem cell technologies, São Paulo State University-

FCAV, Jaboticabal-SP, Brazil

\section{ARTICLE INFO}

Received: 慧 February 11, 2021

Published: 蔧 February 22, 2021

Citation: Amanda Baracho Trindade $\mathrm{H}$ Jonathan Edwin Baracho Trindade $\mathrm{H}$. Mesenchymal Stem Cell Injection Achieves Closure of Chronic Wound in Canine Patient: A Case Report. Biomed J Sci \& Tech Res 34(1)-2021. BJSTR. MS.ID.005497.

\begin{abstract}
Chronic wounds are an important and difficult to manage condition in veterinary medicine. Here we report a case of a chronic wound in a canine patient that had proven resistant to conventional therapies. The wound was treated with a single, local application of mesenchymal stem cells in order to promote wound healing and cicatrization. Mesenchymal stem cells are known to reduce inflammation and scar tissue formation, accelerate the healing process, and exhibit paracrine activity that releases beneficial soluble factors. By 15 days post treatment the wound had closed, the skin had returned to its normal color, and new hair growth could be observed.
\end{abstract}

Abbreviations: MSCs: Mesenchymal Stem Cells; KGF: Keratinocyte Growth Factor; TGF; Transforming Growth Factor

\section{Introduction}

Mesenchymal stem cells (MSCs) represent a type of adult stem cell that can be found in many tissues in the mammalian organism after birth Meirelles, et al. [1] Stem cells are characterized by their ability to self-renew and by their potential to differentiate into functional cells when exposed to the correct stimuli Gazit [2]. Over the past decade, MSCs have received more clinical attention than said types due to a number of characteristics that make them distinct from other stem cell types, particularly regarding their ability to produce bioactive mediators that inhibit scar formation and apoptosis, increase angiogenesis, and stimulate intrinsic progenitor cells to regenerate their functionality Peroni, et al. [3] The advantages of adult-tissue-derived stem cell use that are most pertinent in therapeutics are their ability to differentiate into a range of cell types, their low immunogenicity, and their high antiinflammatory and immunomodulatory potential Meirelles, et al. $[1,3]$

MSCs secrete a number of protein factors, such as $\mathrm{HGH}$, FGF, IGF, EGF, VEGF, STC-1, KGF and SDF-1, which play a role in several biochemical and cellular processes including cellular communication, cellular metabolism, inflammation, tissue repair and regeneration Ramaswamy et al. This wide distribution of biological activities gives MSCs the potential to stimulate diverse cell responses and to interact with other cell types Lai et al. In this context, growth factors, cytokines and microRNAs have been listed as likely effector molecules responsible for the positive results achieved in many studies of cell therapy Salgado et al., Baglio et al., Kapur et al. Here we examine a practical application of the therapeutic potential of MSC: a case of a chronic wound that was healed by a single MSCs injection. A wound is defined as chronic when there is a failure to progress at some point in the three normal stages of healing. The result of this is that after the typical time period for healing has elapsed the tissue injury still has not been repaired Maxson, et al. [4]

\section{Case Report}

A male canine of approximately three years of age and indeterminate breed was adopted 10 months ago in the city of São Sebastião - São Paulo, Brazil. The dog had a chronic wound on its right hind leg that had been present since adoption. Conventional treatments, such as the regular application of antibiotic, antiinflammatory, and epithelizing ointments, were performed on the wound without satisfactory results over a ten-month period after the patient's adoption. At this juncture 2 million canine mesenchymal stem cells were withdrawn from the cell bank at CellTech, a Brazilian company that provides stem cell-based therapies, in order to treat the wound. The cells were injected at the edges of the wound by Dr. Amanda Hill, the CellTech veterinarian. The wound was analyzed at 24 hours, 48 hours, 7 days, 15 days, and 
30 days post injection. Prior to the injection, what skin there was around the wound was thin and glossy (Figure $1 \mathrm{~A}$ ). At just $48 \mathrm{~h}$ post injection it was already possible to observe a reduction in wound size (Figure 1 B). 7 days post injection, scabs had formed, new hair follicle growth could be observed, and the skin around the edge of the wound had thickened considerably (Figure $1 \mathrm{C}$ ). At 15 days post injection, the wound had closed and some areas of skin remained light pink in color while the majority had returned to its normal color (Figure $1 \mathrm{D}$ ). At 30 days post injection the wound remained completely closed, the skin over the wound had achieved normal thickness and durability, and multiple hair follicles can be observed growing over the wound site (Figure 1 E). Importantly, no side effects were observed.

\section{Discussion}

In the present case report, MSCs stimulated the cicatrization of the patient's chronic wound and promoted wound closure. The wound healing process relies on the coordination of cells, growth factors, and extracellular matrix proteins. Due to the fact that MSCs promote wound cicatrization, secrete growth factors and matrix proteins, and recruit other cell types in order to promote a repair response Maxson, et al. [4], they are an excellent candidate for stimulating the natural physiological process of healing. In the present case report, MSCs successfully stimulated the previously stagnant wound healing process. The wound had been present in the animal for at least 10 months, since the date of his adoption if not earlier, and had resisted treatment by other methods such as antibiotic, anti-inflammatory, and epithelizing ointments. By the 15-day post injection evaluation, the wound had closed. It has been put forward that the factors secreted from MSCs, such as VEGF, PDGF, bFGF, EGF, keratinocyte growth factor (KGF), and TGF (transforming growth factor; Gnecchi, et al. [5,6] are responsible for this environmental mediation of the wound area Maxson, et al. [4].

The factors secreted by MSCs regulate inflammation, promote cicatrization, and reduce scarring Ono, et al. [7-9], consequently accelerating wound closure Smith, et al. [10]. In addition, MSCs secrete mitogens that stimulate the proliferation of other cell types such as keratinocytes, dermal fibroblasts, and endothelial cells in vitro Smith, et al. [10,11]. Interestingly, the conditioned medium derived from MSC has been proven to play a role in chemoattraction for macrophages, endothelial cells, epidermal keratinocytes, and dermal fibroblasts in vitro Gurtner, et al. [6,12] Both MSCs and MSC conditioned medium have been shown to promote dermal fibroblasts to accelerate wound closure [4]. It has also been suggested that MSCs may augment the wound's ability to achieve progression beyond the inflammatory phase, avoiding regression to the chronic wound state Maxson, et al. [4] (Figure 1).
A

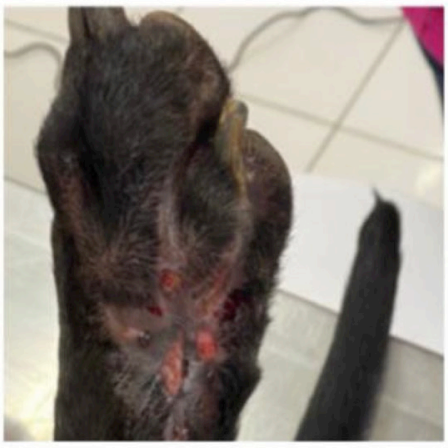

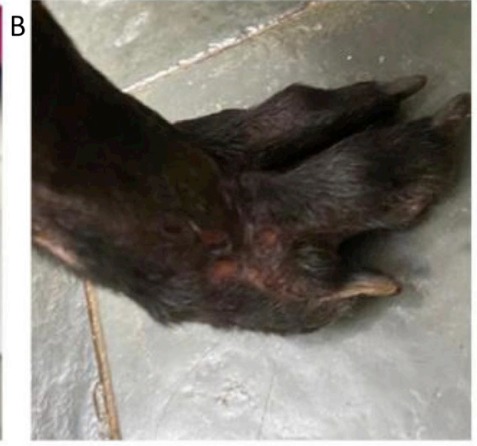
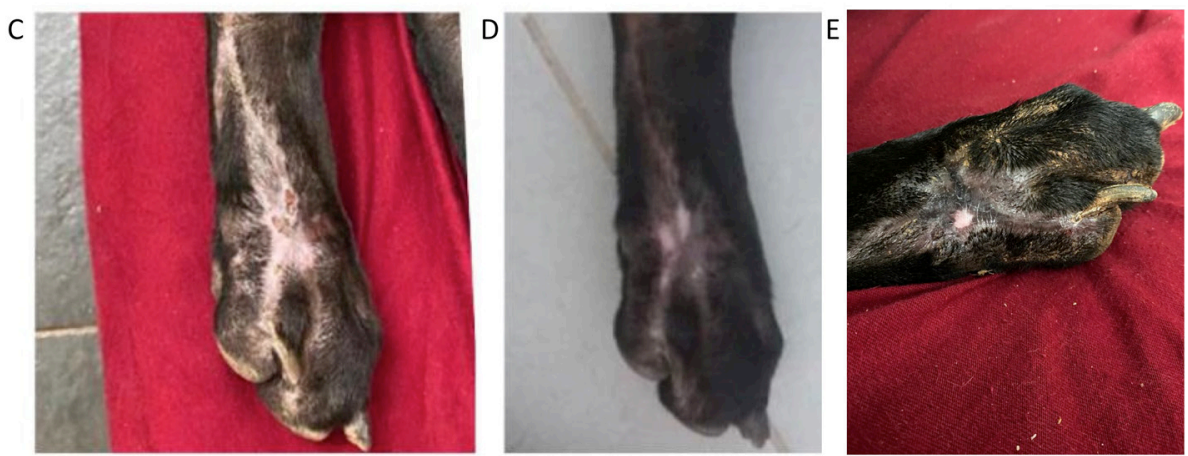

Figure 1:

A) In this picture we can observe the wound in question that had been present for ten months on the day of the injection.

B) 48 hours post injection, a reduction in wound size can be observed.

C) 7 days post injection, we can observe a change in skin color to light pink and the growth of multiple new hair follicles.

D) 15 days post injection, the wound had closed, and the skin continued returning to its normal color.

E) The skin over the wound had achieved normal thickness and durability, and the growth of multiple hair follicles can be observed. 


\section{Conclusion}

The use of cell therapy technologies greatly benefits patients and allows for the employment of personalized therapies and treatments that mitigate chronic and degenerative conditions. Stem cell-based therapies represent a potential solution for various chronic diseases for which current pharmacological treatments have been shown to be ineffective, including chronic wounds. Here, we exhibited a case report in which the patient's chronic wound, that had proved resistant to other therapies, was closed after a single MSC application without any observable side effects.

\section{References}

1. Meirelles LS, Fontes AM, Covas DT, Caplan AI (2009) Mechanisms involved in the therapeutic properties of mesenchymal stem cells. Cytokine Growth Factor Rev 20(5-6): 419-427.

2. Gazit Z, Pelled G, Sheyn D, Kimelman N, Gazit D, et al. (2011) Mesenchymal stem cells. In: Principles of regenerative medicine 17(2): 285-304.

3. Peroni JF, Borjesson DL (2011) Anti-inflammatory and immunomodulatory activities of stem cells. Veterinary Clinics: Equine Practice 27(2): 351-362.

4. Maxson, Scott (2012) Concise review: role of mesenchymal stem cells in wound repair. Stem cells translational medicine 1(2): 142-149.

\section{ISSN: 2574-1241}

DOI: 10.26717/BJSTR.2021.34.005497

Amanda Baracho Trindade Hill. Biomed J Sci \& Tech Res

(c) (P) This work is licensed under Creative

Submission Link: https://biomedres.us/submit-manuscript.php
5. Gnecchi M, Zhang Z, Ni A (2008) Paracrine mechanisms in adult stem cell signaling and therapy. Circ Res 103(11): 1204-1219.

6. Chen L, Tredget EE, Wu PY (2008) Paracrine factors of mesenchymal stem cells recruit macrophages and endothelial lineage cells and enhance wound healing. PLoS One 3: e1886.

7. Ono I, Yamashita T, Hida T (2004) Combined administration of basic fibroblast growth factor protein and the hepatocyte growth factor gene enhances the regeneration of dermis in acute incisional wounds. Wound Repair Re-gen 12(11): 67-79.

8. Shah M, Foreman DM, Ferguson MW (1995) Neutralisation of TGF-beta 1 and TGF-beta 2 or exogenous addition of TGF-beta 3 to cutaneous rat wounds reduces scarring. J Cell Sci 108: 985-1002.

9. Colwell AS, Beanes SR, Soo C (2005) Increased angiogenesis and expression of vascular endothelial growth factor during scarless repair. Plast Reconstr Surg 115(1): 204-212.

10. Smith AN, Willis E, Chan VT (2010) Mesenchymal stem cells induce dermal fibroblast responses to injury. Exp Cell Res 316(1): 48-54.

11. Lee EY, Xia Y, Kim WS (2009) Hypoxia-enhanced wound-healing function of adipose-derived stem cells: Increase in stem cell proliferation and upregulation of VEGF and bFGF. Wound Repair Regen 17(4): 540-547.

12. Gurtner GC, Werner S, Barrandon Y (2008) Wound repair and regeneration. Nature 453: 314-321.

\begin{tabular}{ll} 
BIOMEDICAL & \multicolumn{1}{c}{ Assets of Publishing with us } \\
RESEARCHES & - Global archiving of articles \\
- Immediate, unrestricted online access \\
- Rigorous Peer Review Process
\end{tabular}

